\title{
LA CONSTITUCIÓN DEL DERECHO INTERNACIONAL, EL SUEÑO DE UN REDUCTO JURÍDICO OCCIDENTAL*
}

\author{
THE CONSTITUTION OF INTERNATIONAL \\ LAW, THE DREAM OF A WESTERN \\ JURIDICAL BASTION
}

María Angélica Benavides-Casals**

Fecha de recepción: 28 de mayo de 2016

Fecha de aceptación: 12 de junio de 2016

Disponibilidad en línea: 30 de junio de 2016

\begin{abstract}
PARA CITAR ESTE ARTÍ́CUlO / TO CITE THIS ARTICLE Benavides-Casals, María Angélica, La constitución del Derecho Internacional, el sueño de un reducto jurídico occidental, 28 International Law, Revista Colombiana de Derecho Internacional, 9-48 (2016). http://dx.doi. org/10.11144/ Javeriana.il 14-28.cdis
\end{abstract}

doi:10.11144/Javeriana.il14-28.cdis

* Artículo de reflexión, análisis e investigación.

** Doctora y magíster en Derecho Internacional, Universidad del Sarre, Saarbrücken, Alemania. Diplomada en Derecho Europeo con mención en Derechos Humanos, Universidad del Sarre, Saarbrücken, Alemania. Abogada, Pontificia Universidad Católica de Chile. Profesora, Derecho Internacional Público. Directora de investigación Facultad de Derecho, Universidad Finis Terrae, Santiago, Chile. Agradezco la colaboración de mi ayudante de investigación de la Universidad Finis Terrae, Dennisse Hernández. Contacto: mabenavides@uft.cl 


\section{RESUMEN}

Una discusión - occidental - sobre la existencia de una constitución o constitucionalización del derecho internacional, nos lleva en primer término a plantear el fundamento de validez de ese derecho, que sea plausible según el desarrollo actual de la sociedad internacional, considerando las diferencias entre los ordenamientos jurídicos y culturas de los sujetos que la forman, sumado al fenómeno de la globalización. Luego entramos en una discusión sobre la existencia, la necesidad y la posibilidad de una constitución y constitucionalización del derecho internacional.

Palabras clave: Constitución del derecho internacional; constitucionalización del derecho internacional; fundamento de validez del derecho internacional; globalización 


\section{ABSTRACT}

An-occidental-discussion about the existence of a constitution or constitutionalization of International Law, lead us primarily to raise the validity of a foundation of that right, it's plausibility under the current development of international society, considering the differences between legal systems and cultures of the subjects that form it and globalization. Then we enter a discussion about the existence, the necessity and possibility of a constitution and constitutionalization of International Law.

Keywords: Constitution of international law; constitutionalization of international law; foundation of validity of international law; globalization

\section{SUMARIO}

Introducción.- I. Fundamento de validez del Derecho Internacional Público.- A. Teorías que explican el fundamento de validez del DIP.- 1. Negadores o críticos del Derecho Internacional Público.- 2. Teorías que fundamentan la validez del Derecho Internacional Público.- B. Teorías normativistas. $-C$. Teorías iusnaturalistas.- II. CONSENSO COMO FUNDAMENTO de validez del Derecho Internacional Público y valores como fundamento material.- III. Constitución del Derecho Internacional.- $A$.Constitución del Derecho Internacional Público.- B.- Constitucionalización del DIP.- Conclusiones.- Bibliografía. 
INTRODUCCIÓN

Las sociedades se dotan de sistemas jurídicos que responden a contextos sociales, culturales y económicos de épocas determinadas ${ }^{1}$. Cada una de esas dimensiones ilumina - $\mathrm{u}$ oscurecelas estructuras jurídicas aplicables en el ámbito geográfico en el que el Derecho se despliega. El Derecho es así una realidad determinada por el binomio espacio/tiempo ${ }^{2}$.

El Derecho Internacional Público (DIP), regulando jurídicamente (o intentando regular o aparentando regular, para algunos) la Sociedad Internacional (SI), se ha mostrado particularmente dúctil a que su estructura sea definida por las dimensiones arriba señaladas ${ }^{3}$. Ahora bien, las transformaciones son de largo aliento, sin ser comparables a los cambios que operan en las sociedades nacionales que en pocos años han transformado ámbitos del derecho con nuevos paradigmas. El DIP opera con la rapidez que lo hace el cambio en la sociedad internacional. Lentamente. Otra cosa es que los acontecimientos de connotación internacional se sucedan rápidamente. Los cambios en la estructura, la concepción del DIP y los acontecimientos no se mueven a la misma velocidad.

El cambio en la SI se operó después de la Segunda Guerra Mundial y luego de múltiples guerras; su actual conformación tardó la mitad del siglo XX. Ejemplo de esto es la aceptación de reservas en el nuevo orden mundial para ampliar la sociedad, que presentó la paradoja de una ratificación masiva con reservas de la Convención contra el Genocidio, cuestionablemente contrarias

1 Andreas L. Paulus, Zur Zukunft der Völkerrechtswissenschaft in Deutschland: Zwischen Konstitutionalisierung und Fragmentierung des Völkerrechts, 67 Zeitschrift für ausländisches öffentliches Recht und Völkerrecht, ZaöRV, 695-720, 698 ss. (2007). Disponible en: http://www. zaoerv.de/67_2007/67_2007_3_a_695_720.pdf

2 "Das Recht gilt in der Z Zeit und G Geht mit der Zeit" (El derecho rige en el tiempo y según el tiempo. Traducción propia). Ulrich Fastenrath, Lücken im Völkerrecht, 193 (Duncker \& Humblot, Berlin, 1988).

3 Truyol y Serra señala, citando a sir Paul Vinogradoff, que "las modalidades históricas de organización de las sociedades políticas dan lugar a las diferentes formas con las que el derecho internacional se ha revestido en el transcurso de los siglos". Antonio Truyol y Serra, Historia del derecho internacional público, 17 (Editorial Tecnos, Madrid, 1998). 
al objeto y fin ${ }^{4}$. Es decir, un doble discurso internacional tan pronto terminada la Segunda Guerra Mundial. Otro ejemplo de paradoja es la demora de medio siglo en el establecimiento de una jurisdicción penal internacional.

Atendida la discusión que se ha abierto de parte de la doctrina, resulta imperioso volver a plantearse antiguas preguntas, nuevas cuestiones y presentar posibles respuestas. ¿Por qué? Porque en efecto una parte importante de la sociedad internacional parece haber cambiado, en algunos temas. La pregunta que se deriva aquí es si ese cambio ha sido suficiente para transformar el ordenamiento jurídico de esta sociedad internacional, en lo referido a sus fundamentos de validez. $\mathrm{O}$ bien, por profundos que han sido los cambios, no existe aún la intención positiva de transformación en las bases de lo jurídico y solo se relacionan desde lo político con una perspectiva diferente ${ }^{5}$.

Enfocado en el DIP como instrumento de relación entre sujetos de DIP, y los posibles cambios fundamentales que podría haber experimentado, en el presente trabajo se revisará someramente las teorías que han intentado explicar su fundamento de validez. Luego, se esbozará una teoría que permita recoger la real riqueza y variedad de la sociedad internacional actual. Con base en esto, analizaremos la posibilidad de una "constitucionalización del derecho internacional" como una derivada

4 Las reservas fueron tan numerosas que dieron lugar a una Opinión Consultiva ante la Corte Internacional de Justicia, CIJ. Corte Internacional de Justicia, CIJ, Reservas a la Convención para la Prevención y la Sanción del Delito de Genocidio, Opinión consultiva de 28 de mayo de 1951. Disponible en: http://www.icj-cij.org/homepage/sp/files/sum_1948-1991.pdf, http:// www.dipublico.org/cij/doc/12.pdf

5 Entre las herramientas para relacionarse, la sociedad internacional tiene las relaciones políticas internacionales y el derecho. Celestino del Arenal, La teoría de las relaciones internacionales hoy: debates y paradigmas, 22 Revista de Estudios Internacionales de la Universidad de Chile, 86, 153-182 (1989). Disponible en: http://www.revistaei.uchile.cl/index.php/REI/article/ view/15594. Esther Barbé, El papel del realismo en las relaciones internacionales (La teoría politica internacional de Hans J. Morgenthau), 57 Revista de Estudios Politicos, Nueva Época, 149-176 (1987). Disponible en: http://www.cepc.gob.es/publicaciones/revistas/revistaselectro nicas?IDR=3\&IDN=215\&IDA=16415, https://dialnet.unirioja.es/ejemplar/3269. Esther Barbé, Relaciones internacionales ( $2^{\mathrm{a}}$ ed., Tecnos, Madrid, 2006). Para una interesante discusión sobre relación de teoría política y derecho, ver Armin von Bogdandy \& Jürgen Habermas, Diskurstheorie und Völkerrecht: Ein Interview mit Jürgen Habermas, 73 Zeitschrift für ausländisches öffentliches Recht und Völkerrecht, ZaöRV, 295-303, 298 ss. (2013). 
supuestamente obvia, atendido el profundo cambio de la sociedad internacional.

Este trabajo parte de la premisa de que aquellas teorías que fundamentan la validez pero obvian la diversidad esencial de los sujetos que interactúan en la SI contemporánea ${ }^{6}$, no permitirían dar sustento a una posible constitución internacional. Y sumado a esto, en lo relativo al concepto "constitución" aplicado al DIP, el trabajo parte de la premisa de que un proceso de constitucionalización deriva necesariamente del fundamento de validez que se logre tener por válido o al menos por suficiente.

\section{FUNDAMENTO DE VALIDEZ DEL DERECHO} INTERNACIONAL PÚBLICO

Al parecer, la discusión por el fundamento de validez del DIP si no está olvidada, al menos está relegada a una de aquellas de menor prioridad ${ }^{7}$. Considerar que es una discusión sin importancia práctica ${ }^{8}$, superficialmente observando, bien puede tener una arista de realismo, dado el comportamiento de los estados: ellos se conducen de acuerdo al derecho internacional, no niegan su existencia y justifican (aun lo injustificable) mediante normas (a veces, mal invocadas) de DIP.

Sin embargo, el fundamento de validez permite analizar las normas actuales, y las que están en ciernes desde la perspectiva correcta: cómo y por qué nacen, por qué se cumplen, por qué no, por qué los estados se sienten (o no) compelidos a guiarse por algunas y por tanto, a aceptar su obligatoriedad y así conducirse de acuerdo a ellas, y cuál (de existir) sería el fundamento que le da sustento a una supuesta constitución internacional. La búsqueda de ese fundamento y su permanente discusión permiten sostener en un paso posterior, que abordaremos en un

6 En especial, la diversidad de estados y sus sociedades nacionales.

7 Stefan Kadelbach, Völkerrecht als Verfassungsordnung? Zur Völkerrechtswissenschaft in Deutschland, 67 Zeitschrift für ausländisches öffentliches Recht und Völkerrecht, ZaöRV, 599-621, 606 (2007). Disponible en: http://www.zaoerv.de/67_2007/67_2007_3_a_599_622. pdf

8 Wolfgang Graf Vitzthum, Völkerrecht, 31 (4a ed., De Gruyter Recht, Berlin, 2007). 
estudio siguiente, el ámbito de la responsabilidad internacional contenida en el principio general del DIP pacta sunt servanda, que encuentra una manifestación convencional en el artículo 27 de la Convención de Viena ${ }^{9}$, en relación con la forma y oportunidad de cumplimiento en el ámbito nacional de las normas de derecho internacional.

Andreas L. Paulus - parafraseando a sir Hersch Lauterpacht ${ }^{10}$ - sostiene que tratar sobre DIP es ir a los límites del derecho. Y no deja de tener razón aun en los tiempos actuales.

Sin embargo, sostenemos que el DIP es derecho, y como tal, su fundamento de validez existe. Si bien quizás no es posible llegar a una respuesta unívoca, no por difícil debe ser abandonada su búsqueda ${ }^{11}$. Ese fundamento de validez es el que permite sostener la obligatoriedad del DIP, y entender la génesis y validez de la pretendida constitución internacional.

\section{Teorías que explican el fundamento de validez del DIP}

Las teorías que buscan el fundamento de validez del DIP están impregnadas del orden mundial existente en la época del nacimiento, auge y cuestionamiento de sus normas y son va-

9 Organización de Naciones Unidas, ONU, Convención de Viena sobre el Derecho de los Tratados, U.N. Doc A/CONF.39/27 (1969), 1155 U.N.T.S. 331, Viena, 23 de mayo de 1969, entrada en vigencia 27 de enero de 1980. Disponible en: http://legal.un.org/diplomaticconferences/ lawoftreaties-1969/docs/english/confdocs/a_conf_39_27.pdf, https://www.oas.org/dil/esp/ Convencion_de_Viena_sobre_derecho_tratados_Colombia.pdf

10 Andreas L. Paulus, Zür Zukunft der Völkerrechtswissenschaft in Deutschland: Zwischen Konstitutionalisierung und Fragmentierung des Völkerrechts, 67 Zeitschrift für ausländisches öffentliches Recht und Völkerrecht, ZaöRV, 695-720, 697 (2007). Disponible en: http://www. zaoerv.de/67_2007/67_2007_3_a_695_720.pdf

11 Stefan Kadelbach sostiene que se ha reabierto una nueva discusión sobre el fundamento de validez, debido al planteamiento de una posible constitución internacional. Stefan Kadelbach, Völkerrecht als Verfassungsordnung? Zur Völkerrechtswissenschaft in Deutschland, 67 Zeitschrift für ausländisches öffentliches Recht und Völkerrecht, ZaöRV, 599-621, 620 (2007). Disponible en: http://www.zaoerv.de/67_2007/67_2007_3_a_599_622.pdf 
riadas $^{12}$. Muy simplificadamente expuesto ${ }^{13}$, están aquellos que lo fundamentan en el derecho natural, aquellos en el derecho positivo, aquellos que simplemente niegan su existencia como derecho, y una multiplicidad de variantes de las dos primeras.

\section{A. Negadores o críticos del Derecho Internacional Público}

Ya desde Thomas Hobbes la idea de un derecho entre estados soberanos es un imposible ${ }^{14}$. La sola representación de un poder superior al Leviatán sería una contradicción con la idea de poder soberano absoluto erigido para protegerse de otros y dominar a esos otros. Luego, a su turno, Georg Wilhelm Friedrich Hegel ${ }^{15}$ sostiene la imposibilidad de que los estados creen estructuras superiores a las que puedan someter su voluntad, ellos - los que en sí tienen el poder total— no podrían someterse. Sostiene: "das Volk als Staat ist der Geist in seiner substantiellen Vernünftigkeit und unmittelbaren Wirklichkeit, daher die absolute Macht auf Erde"16.

Entre los imprescindibles negadores del Derecho Internacional Público, se encuentran Jack L. Goldsmith y Eric A. Posner ${ }^{17}$.

12 Karl Döhring, Völkerrecht, 3 (2 $2^{\mathrm{a}}$ ed., C. F. Müller Verlag, Heidelberg, 2004). Una clara y completa exposición sobre las diversas teorías en Stefan Kadelbach, Völkerrecht als Verfassungsordnung? Zur Völkerrechtswissenschaft in Deutschland, 67 Zeitschrift für ausländisches öffentliches Recht und Völkerrecht, ZaöRV, 599-621, 599 ss. (2007). Disponible en: http://www.zaoerv. de/67_2007/67_2007_3_a_599_622.pdf. Harold Hongju Koh aborda una clasificación según la "cuestión de cumplimiento" y las resume en realistas, racionalistas, kantiana y procesal. Harold Hongju Koh, ¿Por qué las naciones obedecen al Derecho Internacional?, 63 Thèmis Revista de Derecho, 11-50, 17 ss. (2013). Disponible en: http://revistas.pucp.edu.pe/index.php/ themis/article/view/8988/9394

13 No resulta eficiente para este trabajo referirse a cada una de ellas de forma exhaustiva, pues se presupone el conocimiento que el lector tiene de las más significativas. El presente trabajo pretende encontrar ese fundamento por un camino diverso y ver en qué medida sirve para la pretendida constitución internacional de la que algunos hablan.

14 Thomas Hobbes, Leviatán o la materia, forma y poder de un estado eclesiástico y civil, Capítulos 13, 17, 26 (2 reimp., Alianza Editorial, Madrid, 2011).

15 Georg Wilhelm Friedrich Hegel, Principios de la filosofia del Derecho o Derecho natural y ciencia política, 331 ( $2^{\mathrm{a}}$ ed. Edhasa, Barcelona, 1999).

16 "El pueblo como estado es el espíritu, en su racionalidad sustancial y realidad directa e inmediata, y de ahí su poder absoluto sobre la tierra". Traducción propia.

17 Aun cuando no se consideran a sí mismos como tales, su contumaz negación de la vinculación del DIP solo puede leerse como una negación de la existencia del derecho como tal. Jan Wiegandt, Internationale Rechtsordnung oder Machtordnung? Eine Anmerkung zum Verhältnis von Macht und Rech im Völkerrecht, 71 Zeitschrift für ausländisches öffentliches Recht und Völkerrecht, ZaöRV,31-76, 46 ss. (2011). Disponible en: http://www.zaoerv.de/71_2011/71_2011_1_a_31_76. 
Para ellos, el DIP no es más que un instrumento utilitario a los fines e intereses de los estados y un vehículo para maximizar intereses y resultados convenientes ${ }^{18}$. Sin autodefinirse como negadores, al negar la obligatoriedad del Derecho Internacional Público, en sus afirmaciones se aprecia por tanto una negación de su calidad de Derecho ${ }^{19}$. Para ellos, el DIP no es vinculante pero sí necesario, partiendo de la base de los intereses de los estados y la definición y distribución de poder. Los estados se conducirían mediante lo que ellos llaman la teoría de las elecciones racionales ${ }^{20}$. El Derecho Internacional y en especial el convencional serían equiparables a declaraciones de intenciones sin carácter jurídico, y su objetivo es la relación entre estados para el máximo provecho en la consecución de intereses ${ }^{21}$. El derecho convencional no pasaría de ser declaraciones de intenciones protectoras de intereses, que explican la necesaria intervención de órganos internos que permitan una discusión sobre esos intereses en juego y muestren al otro interviniente en el tratado, la disposición para el apoyo político de esa contraparte. Por otro lado, el tratado permitiría el establecimiento de una serie de reglas de interpretación, por ejemplo o certezas en los límites del acuerdo.

Equiparables a los negadores están los contrarios al DIP. Sin negar su existencia, basan su razón de ser en un escenario conveniente a los intereses estatales, que mediante una aparente estructura jurídica, dota a este "derecho" de las credenciales ne-

pdf. Comparar con Hans-Joachim Cremer, Völkerrecht - Alles nur Rhetorik?, 67 Zeitschrift für ausländisches öffentliches Recht und Völkerrecht, ZaöRV, 267-296 (2007). Disponible en: http://www.zaoerv.de/67_2007/67_2007_2_267_296.pdf, http://www.zaoerv.de/67_2007/vol67. 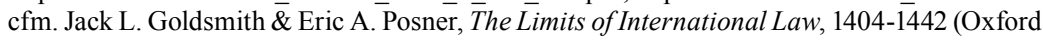 University Press, Oxford, 2005).

18 Ibíd.

19 Hans-Joachim Cremer, Völkerrecht - Alles nur Rhetorik?, 67 Zeitschrift für ausländisches öffentliches Recht und Völkerrecht, ZaöRV, 267-296, 268 ss. (2007). Disponible en: http://www. zaoerv.de/67_2007/67_2007_2_267_296.pdf, http://www.zaoerv.de/67_2007/vol67.cfm

20 Hans-Joachim Cremer, Völkerrecht - Alles nur Rhetorik?, 67 Zeitschrift für ausländisches öffentliches Recht und Völkerrecht, ZaöRV, 267-296, 269 (2007). Disponible en: http://www. zaoerv.de/67_2007/67_2007_2_267_296.pdf, http://www.zaoerv.de/67_2007/vol67.cfm

21 Una crítica intensa y extensa a esta perspectiva en Hans-Joachim Cremer, Völkerrecht - Alles nur Rhetorik?, 67 Zeitschrift für ausländisches öffentliches Recht und Völkerrecht, ZaöRV, 267-296, 274 (2007). Disponible en: http://www.zaoerv.de/67_2007/67_2007_2_267_296.pdf, http://www.zaoerv.de/67_2007/vol67.cfm 
cesarias para ir tras los propios intereses estatales. Así, Hans J. Morgenthau ve en los intereses y la forma de sobreponerse a los otros, no una imposibilidad del DIP, pero sí una serie de requisitos antes de que este pueda aparecer (al menos, formalmente): intereses particulares inexistentes y estructuras centrales, entre otros $^{22}$. Así el Derecho Internacional Público se presenta como una realidad, pero débil, carente de existencia por sí misma y solo tributaria a la consecución de los fines del estado.

En una línea parecida, pero con otros elementos, la teoría de la Escuela de New Haven ${ }^{23}$ explica el DIP como un proceso, en que el análisis de decisiones políticas tendría una parte central $^{24}$. No puede negarse la relación efectiva entre política y derecho, y en esto aciertan. ¿Pero acaso no hacen eso todas las sociedades? ¿No se regula acaso solo aquello que las sociedades definen como intereses, o bienes, o valores o como sea que los conceptualicen, según las categorías filosóficas en las que basan el derecho interno? Sin embargo, esta Escuela va más allá. Para sus seguidores, la respuesta está dada por el decisor, quien recoge elementos extralegales y se sale de la norma. En este punto, la teoría es discutible, ya que el reconocimiento de una norma jurídica presupone su existencia con parámetros formales y preestablecidos que no autorizan a salirse de ellos, quedando solo la vía interpretativa, que en Derecho Internacional, al menos y por texto expreso de la Convención de Viena, obedece a un criterio objetivo y no subjetivo de interpretación.

22 Hans J. Morgenthau, Politics among Nations: the Struggle for Power and Peace, 283 ss. ( $7^{\mathrm{a}}$ ed., McGraw-Hill Higher Education, Boston, 2006).

23 Ver crítica a esta escuela en Harold Hongju Koh, ¿Por qué las naciones obedecen al Derecho Internacional?, 63 Thēmis - Revista de Derecho, 11-50, 24 ss. (2013). Disponible en: http:// revistas.pucp.edu.pe/index.php/themis/article/view/8988/9394. En general, la doctrina estadounidense de DIP es práctica y realista. Anne Peters, Die Zukunft der Völkerrechtswissenschaft: Wider den epistemischen Nationalismus, 67 Zeitschrift für ausländisches öffentliches Recht und Völkerrecht, ZaöRV, 721-776, 769 (2007). Disponible en: http://www.zaoerv. de/67_2007/67_2007_3_a_721_776.pdf

24 Jan Wiegandt, Internationale Rechtsordnung oder Machtordnung? Eine Anmerkung zum Verhältnis von Macht und Rech im Völkerrecht, 71 Zeitschrift für ausländisches öffentliches Recht und Völkerrecht, ZaöRV, 31-76, 44 (2011). Disponible en: http://www.zaoerv. de/71_2011/71_2011_1_a_31_76.pdf 
La más típica de las críticas al DIP como derecho sería la dificultad o imposibilidad de exigir su cumplimiento ${ }^{25}$. Esta es la crítica predilecta de los negadores o contrarios del DIP. A priori, parece una crítica convincente. Nadie ve una policía mundial, un tribunal con jurisdicción obligatoria universal, un aparato administrativo que fiscalice el cumplimiento de penas o sanciones asociadas a las violaciones, y que estas sean estructuras permanentes, con funcionarios, con rangos, con distribución de tareas administrativas, etc. Es decir, nadie ve todo ese aparato tan típicamente nacional, local, en fin, tan doméstico y tan cercano a esas categorías que manejamos cotidianamente cuando miramos nuestros ordenamientos y estructuras nacionales.

Sin embargo, parece una crítica encajonada en conceptos y categorías que simplemente no obedecen a aquellas en las que se mueve el DIP y la forma en que los miembros de la sociedad internacional han acordado estructurar jurídica y políticamente sus relaciones.

La exigencia jurídica de cumplimiento plantea la necesidad de una estructura, establecida por los miembros de la comunidad. Esa estructura en DIP existe, tanto en forma como en fondo e instrumentos.

Ahora bien, el derecho requiere normas secundarias que permitan su exigencia compulsivamente. Y el DIP las conoce. Y corresponden a dos constelaciones. Las primeras son aquellas contenidas en las competencias entregadas a los órganos erigidos por los estados en las organizaciones o instancias que han acordado crear para decidir si hay o no violación de normas. Y solo obliga y por tanto están expuestos a su exigencia, a aquellos que han entrado en esa relación jurídica. Las segundas son aquellas sanciones que los estados tienen para exigir el cumplimiento de lo definido por una instancia internacional y las que utilizan además cuando no existiendo esas instancias, se produce una

25 Jan Wiegandt, Internationale Rechtsordnung oder Machtordnung? Eine Anmerkung zum Verhältnis von Macht und Rech im Völkerrecht, 71 Zeitschrift für ausländisches öffentliches Recht und Völkerrecht, ZaöRV, 31-76, 48 (2011). Disponible en: http://www.zaoerv. de/71_2011/71_2011_1_a_31_76.pdf 
violación de la norma jurídica: las represalias, las retorsiones, las contramedidas.

Pero claro, esta sociedad internacional no es ninguna de las múltiples sociedades nacionales que existen (cada una con sus particularidades jurídicas, económicas, sociales, culturales, etc.). Esta sociedad internacional está integrada por diversos sujetos que interactúan en distintas esferas y ámbitos. Y cuando se relacionan mediante el Derecho Internacional Público solo se consideran aquellos sujetos que los propios creadores del DIP han definido como tales, primordialmente estados y las organizaciones internacionales en sus ámbitos específicos de acción. Y en ese ámbito de relación, en el jurídico, los estados no olvidan sus relaciones internacionales cuando evalúan exigir cumplimiento. Esto no significa que la norma que obliga a cumplir y los mecanismos para hacerlo sean inexistentes. Ocurre simplemente que los estados — según intereses y ponderaciones de orden que van más allá de lo jurídico-deciden activar o no los mecanismos de coerción. Así mismo ocurre cuando una organización o un órgano de una organización evalúan la imposición de sanciones, y lo hacen en el marco de las funciones y competencias que los estados al crear esa organización u órgano de la organización les han otorgado. Es posible criticar la falta de democracia en el Consejo de Seguridad de Naciones Unidas, por ejemplo, su inacción en ciertos eventos acaecidos, pero ese es el orden institucional y jurídico creado por los estados. La disponibilidad de la exigibilidad de la norma jurídica no contradice su naturaleza jurídica. Responde simplemente a la estructura del ordenamiento jurídico que los creadores del derecho han decidido ${ }^{26}$. La norma que contiene el derecho y su sujeto existe; así como existe la norma, independiente de la fuente que la contiene, que permite su coerción activando los mecanismos de exigibilidad. Aquellos que critican el DIP por una supuesta "falta de coercibilidad" solo observan el fenómeno

26 Su necesaria reforma es tema de otros estudios y dependerá de los consensos que se logren en el sistema que los estados han creado para que el DIP se despliegue. 
jurídico internacional desde perspectivas y nociones nacionales: instancias centralizadas encargadas de compulsión en caso de violación de las normas jurídicas internas ${ }^{27}$. Resulta sorprendente que el DIP sea analizado con categorías aplicadas a sistemas nacionales para así fundamentar la negativa a su existencia.

Aquellos que niegan el DIP como Derecho lo hacen en definitiva amparados en el argumento central de su carencia de un sistema y autoridad superior que monopolice el cumplimiento forzado de las normas, a más de la inexistencia de un ente centralizado que "legisle". En relación con lo primero, el DIP solo lo tiene en función de un imperativo jurídico que es la prohibición y amenaza del uso de la fuerza. Para el resto de los imperativos jurídicos, se crean instancias particulares de variada naturaleza, o bien se pueden ejercer represalias, retorsiones o contramedidas por los propios afectados luego de un juego de ponderación de conveniencia. En relación con el segundo - la inexistencia de un legislador central-, es solo una reafirmación de un punto de vista estrechamente doméstico, que desconoce por lo demás que en los circuitos nacionales quien legisla es una autoridad que tiene esa potestad en virtud de una ley superior, natural, racional, consensual, etc., la que sea que se plantee como cierta por el sistema interno. Y por lo demás, la creación de la norma no siempre deriva de un legislador centralizado, por ejemplo, los contratos. Lo interesante es que en DIP los sujetos imperados crean así mismo estas normas, como en el caso de los contratos en derecho nacional. ¿Y qué da el fundamento de validez a esa norma generada? Eso es lo importante a desentrañar.

27 Sin que corresponda hacer paralelos entre ambos sistemas normativos, nacional o internacional, ya que precisamente se sostiene aquí que no son comparables, se podemos señalar que olvidando sin embargo, que no toda norma nacional tiene una exigencia de cumplimiento forzada, ya que hay acciones de las que dispone el sujeto activo. 


\section{B. Teorías que fundamentan la validez del Derecho Internacional Público}

La cantidad de teorías que pretenden explicar el fundamento de validez del derecho internacional es inmensa como el océano. Una sistematización conceptual siguiendo a Knut Ipsen, considera teorías voluntaristas, normativistas y naturalistas $^{28}$.

Dejaremos las primeras, basadas en la voluntad estatal, para un apartado siguiente, y nos haremos ahora cargo de las normativistas y de las naturalistas.

\section{Teorías normativistas ${ }^{29}$}

Aquí la principal es la teoría de Hans Kelsen, quien encuentra el fundamento de validez de la norma internacional en el propio sistema normativo que resultaría coherente y autosuficiente y reconoce su fundamento en la que denomina Grundnorm. A ella llega buscando una norma superior que por materia, procedimiento y autoridad, otorgue fundamento a la inferior. Sin embargo, Kelsen mismo pone el cimiento del DIP, específicamente de todo el Derecho, en una norma que está más allá de lo positivo. Su norma fundamental e hipotética sería el principio pacta sunt servanda. Contradiciendo toda su teoría, este principio no tiene proceso de formación, autoridad competente, ni otra que sea superior de la cual derive. Es decir, el pacta sunt servanda es una especie de supuesto normativo necesario, pero carente de todas las exigencias que él señala para cada una de las normas del sistema. Contradicción en estado puro. Además, resulta sorprendente que Kelsen aparte de su teoría la voluntad del Estado que, más allá de los aspectos formales de producción jurídica, imprime el contenido normativo, la intencionalidad ya sea de consolidar una sociedad según su estadio temporal actual o de promoverla en una dirección determinada. Olvida así,

28 Knut Ipsen, Völkerrecht, 7 ss. (C. H. Beck, München, 2004).

29 No nos extenderemos en detalle en esas teorías, que asumimos conocidas por el lector. 
creemos, que la norma es un vehículo y no un fin para regular las relaciones que se dan en una sociedad entre los individuos. Además, los sistemas jurídicos puros, como lo planteó Kelsen, olvidan las cargas valóricas (o disvalóricas) de las sociedades, que las impulsan a regularse jurídicamente de una forma determinada. El Derecho no es pura forma o formalidad, tampoco es un constructo matemático de producción. Es un equilibrado, o desequilibrado, sistema regulador de organización social.

2. Teorías iusnaturalistas ${ }^{30}$

Este campo es amplio, amplísimo en los fundamentos diversos que se dan a un derecho natural ${ }^{31}$. Un derecho - es decir, un sistema de producción, vigencia, ejecución y coherencia de normas jurídicamente vinculantes, obligatorias para los sujetos de derecho - tendría una justificación primaria y esencial más allá, previa e independiente de los productores de normas, de los imperados y de los momentos históricos que influyen poderosamente en la estructura y contenido del derecho. Tomás de Aquino, Francisco de Vitoria, Francisco Suárez, Jean Jacques Rousseau, Alfred Verdross, Hermann Mosler, Friedrich A. Hayek y Ronald Dworkin, entre muchísimos otros con variantes de todo tipo.

El espectro de fundamentaciones naturalistas es tan amplio como conocido. Si tuviese que señalarse un mínimo común a las críticas de las teorías iusnaturalistas teológicas son el fundamento en el derecho divino que tiene el derecho positivo. Es decir, no solo algo "connatural" en el hombre impregnado por la divinidad, sino que la crítica vendría dada porque eso "connatural" constituye un orden jurídico del que se debe derivar el orden jurídico positivo para ser válido. La crítica apuntaría también a que siendo las sociedades religiosamente diferentes,

30 No nos extenderemos en detalle en esas teorías, que asumimos conocidas por el lector.

31 Hans-Joachim Cremer, Völkerrecht - Alles nur Rhetorik?, 67 Zeitschrift für ausländisches öffentliches Recht und Völkerrecht, ZaöRV, 267-296, 284 ss. (2007). Disponible en: http://www. zaoerv.de/67_2007/67_2007_2_267_296.pdf, http://www.zaoerv.de/67_2007/vol67.cfm 
costaría encontrar una que fuese la correcta y diese el fundamento de validez al derecho positivo internacional, común a todos los sujetos de derecho internacional existentes, independientes de su concepción religiosa ${ }^{32}$.

El iusnaturalismo no teológico racionalista funda su validez en aquello de común que hay en la naturaleza del hombre, no derivado de una divinidad, y que le otorga derechos innatos. Para ello sería necesario partir de una naturaleza y estructuras de sociedades a las que el hombre naturalmente tiende.

El iusnaturalismo contemporáneo, que en derecho internacional tiene uno de sus exponentes principales en Alfred Verdross, sostiene que siendo natural la vida en sociedad y el hombre tiende a ella, las condiciones sociales de ayuda mutua, y el fundamento de ayuda y el establecimiento de las normas de DIP naturalmente serían los valores e intereses comunes entre los estados ${ }^{33}$.

Este trabajo es un intento de encontrar elementos que permitan acercarse a un fundamento de validez del DIP y, por tanto, de validez de un derecho aplicable a sujetos de derecho internacional, que se relacionan de forma muy dispar, y tienen fundamentos de sus derechos nacionales muy disímiles también. Si es posible obtener una aproximación a un fundamento de validez común para la estados, será posible acercarse a una eventual constitución internacional existente, en ciernes o (im)posible.

Hablamos de una dispar forma de relacionarse de los sujetos de DIP, toda vez que, por ejemplo, la filiación a la única organización internacional de vocación universal con cuestionamientos, que tiene conocidas críticas democráticas en los procesos de toma de decisiones vinculantes y que, a la vez, no tiene función normativa obligatoria para todos los estados en todos los ámbitos en que se despliega el DIP, resulta de alta complejidad la enunciación de un fundamento que no sea otro que el que recoja esta forma de relación jurídica. No se discute en este trabajo

32 Karl Döhring, Völkerrecht, 6 ss. (2 ${ }^{\mathrm{a}}$ ed., C. F. Müller Verlag, Heidelberg, 2004).

33 Harold Hongju Koh, ¿Por qué las naciones obedecen al Derecho Internacional?, 63 Thēmis - Revista de Derecho, 11-50, 19 (2013). Disponible en: http://revistas.pucp.edu.pe/index.php/ themis/article/view/8988/9394. Alfred Verdross, Universelles Völkerrecht Theorie und Praxis, 327 ss. ( $3^{\mathrm{a}}$ ed., Duncker \& Humblot, Berlin, 1984). 
que, para el orden nacional, cada estado y por tanto los grupos humanos que lo conforman opten por un fundamento u otro de su ordenamiento jurídico, y que incluso haya (como es) diversas teorías dentro del estado que pugnan entre sí constantemente para ser consideradas la teoría que da fundamento al derecho nacional respectivo.

Pero para el ordenamiento internacional y debido a la compleja sociedad que regula, quizás se requieren la creatividad y el reconocimiento de estos disímiles fundamentos, tanto teóricos como prácticos, reflejados en los diversos ordenamientos y doctrinas nacionales y que esto nos lleve al encuentro de un camino intermedio. El derecho de los diversos estados no se define si es positivista, iusnaturalista teológico o axiológico, etc. Más bien los estudios de la doctrina que subyace a sus normas fundamentales, a la jurisprudencia de las más altas judicaturas nacionales, al análisis de la forma de llevar adelante las discusiones de creación normativa y, en fin, de la doctrina de los más significativos estudiosos del derecho doméstico, dan las pistas para descubrir si es o no un estado regido por un derecho con una $\mathrm{u}$ otra fundamentación ${ }^{34}$. La unidad del derecho nacional con el DIP, como un sistema coherente y completo en sí mismo tanto en las normas que regulan ámbitos diversos como el nacional y el internacional ${ }^{35}$, parece no ser posible. Los estados, independiente del fundamento de validez que atribuyan a su derecho, se relacionan con otros estados, que tienen a su vez otras fundamentaciones. El derecho - lo señalamos a riesgo del horror que pueda significar para algunos teóricos del derecho - no tiene una única fundamentación cuando hablamos de órdenes diversos como el nacional o el internacional, sobre todo para aquellos tan aferrados a conceptualizaciones domésticas.

34 Chile, por ejemplo, en su Constitución, artículo 5, establece el respeto a los derechos esenciales que emanan de la naturaleza humana. Puede haber una discusión eterna sobre el fundamento escogido por el creador de la norma, pero no puede abstraerse del importante componente iusnaturalista que este artículo demuestra. Chile, Constitución, 11 de septiembre de 1980, actualizada por la Ley 20.860, 20 de octubre de 2015. Disponible en: https://www.leychile.cl/ Navegar?idNorma $=242302$

35 En fin, una aproximación extrema ya sea kelseniana o iusnaturalista. 
¿Requiere el DIP un fundamento de validez idéntico al que se predica de los ordenamientos nacionales? O más bien, ¿resiste el DIP un fundamento de validez de aquellos que intentan sostener el derecho nacional? La pregunta no es baladí, no atenta contra la ciencia del Derecho y en ella puede encontrarse una respuesta, al menos aproximada, a por qué este derecho existe y rige, con base en diversos criterios, razones y elementos del derecho nacional y la multiplicidad de fundamentos que de este último se predican.

En el apartado siguiente, se entregan elementos que permiten optar o al menos presentar como aceptable, un fundamento de validez basado en el consenso, en la voluntad de las partes creadoras de normas, pero atizada con aspectos axiológicos, como un elemento que se deriva del análisis del contenido normativo de las diversas fuentes del derecho internacional contemporáneo. No pretende ser original, pero sí apoyar a aquellos que, tomando elementos de este camino, intentan fundamentar el DIP en aquello que es dable para darle validez.

\section{Consenso como Fundamento de VAlidez Del Derecho InTernacional Público y VALORES COMO FUNDAMENTO MATERIAL}

Atendida la perspectiva cuantitativa y de contenido de las múltiples fuentes del derecho internacional vigente, es posible sostener que los estados se relacionan mediante normas a las cuales les atribuyen carácter jurídico. Esto se reconoce al menos en los múltiples tratados firmados; las costumbres a que están sujetos y consideran vinculantes; en aquellos actos jurídicos unilaterales a los cuales se atienen una vez formulados, y en el cumplimiento mayoritario de las sentencias internacionales dictadas por los diversos tribunales internacionales existentes. Pero esto podría no pasar de ser un mero cúmulo de documentos, declaraciones, tradiciones, que los estados en sus relaciones internacionales 
suscriben o acogen. Sin embargo, dos elementos indican que los adoptan y reconocen como derecho.

En primer lugar, la pertenencia de los estados a organizaciones internacionales que tienen como fundamento normativo un instrumento jurídico, de la que emanan entre otras, competencias. Así, los estados no discuten por ejemplo que la ONU es una organización entre cuyas funciones está desarrollar el derecho internacional mediante la Comisión de Derecho Internacional o por medio de las organizaciones que forman el sistema de Naciones Unidas. Sin embargo, esto podría así mismo no pasar de ser una postura adoptada para convivir civilizada y ordenadamente entre iguales, sin reconocer necesariamente carácter de derecho a los tratados que, por ejemplo, fundan esas organizaciones o aquellos que en su seno se aprueban y luego los estados ratifican.

Pero en segundo lugar, los estados han relacionado sus derechos domésticos con este derecho internacional, mediante mecanismos diversos, que van desde declaraciones expresas en sus normas internas que persiguen la incorporación del DIP, o bien vías judiciales o de administración que dan a este derecho internacional un lugar (con diversos matices) dentro de sus ordenamientos.

El porqué el DIP existe, rige y es conceptualizado como derecho por los sujetos de derecho internacional, debe llevar solo a una consecuencia lógica. Es derecho. Esta afirmación - que parece simplista - puede darnos una primera y simple respuesta: si los estados se comportan de acuerdo a DIP, al menos en algunos ámbitos, es porque lo consideran derecho, al menos en esos ámbitos y respecto de esas normas. La pregunta realmente importante es por qué lo consideran tal, por qué lo cumplen y lo invocan (aun cuando sea selectivamente). Ahí radica su fundamento de validez.

El DIP conoce de una historia de vigencia, con luces y sombras, con mayor o menor "prestigio", con más o menos sujetos involucrados, con más o menos eficacia, y esto no deja 
de sorprender. No por nada Christian Hillgruber sostiene que impresiona la "continuidad de sus estructuras fundamentales" 36 .

El único fundamento plausible que se puede señalar para el derecho internacional es el consenso y el consentimiento entregado para formarlo. Francisco Orrego-Vicuña aclara que es precisamente el consenso el que permite la mantención en el tiempo de este derecho, no siendo un derecho de mayorías ${ }^{37}$.

Knut Ipsen ${ }^{38}$ expone acertadamente las distintas teorías que sustentan el fundamento de validez en la voluntad, que llamaremos consenso ${ }^{39}$. La Selbstverpflichtungslehre, de Georg Jellinek ${ }^{40}$, tributa a su teoría sobre el estado. Las normas de DIP solo lo son por aceptación del estado en la medida en que sirvan a sus intereses y pueden por tanto dejar de serlo por la misma voluntad. $\mathrm{Su}$ nacimiento y vigencia (que incluye el desde y el hasta cuándo está vigente para ese estado) dependen de la voluntad estatal. Ya en el Caso Lotus, la Corte Internacional de Justicia asume la teoría voluntarista ${ }^{41}$.

Se podría sostener que la incorporación de nuevos sujetos de DIP erosiona la teoría del consenso estatal en la formación del DIP. Esto no es así, porque con matices, los estados siguen siendo los creadores primarios de las normas, y son ellos los que crean o elevan a la categoría de sujeto a otros entes, atribu-

36 Christian Hillgruber, Kontinuität und Wandel in der Entwicklung des Völkerrechts, en Recht und Rechtswissenschaft. Signaturen und Herausforderungen zum Jahrtausendbeginn, 117-132, 131 (Peter-Christian Müller-Graff, verlag, Universität Heidelberg, Juristische Fakultät: Recht und Rechtswissenschaft, Heidelberg, 2000).

37 Francisco Orrego-Vicuña, El derecho internacional: entre el cambio y la disolución, 39 Revista de Estudios Internacionales de la Universidad de Chile, 54, 57-66, 65 (2006). Disponible en: http://www.revistaei.uchile.cl/index.php/REI/article/viewPDFInterstitial/14471/14784

38 Comparar con Karl Döhring, Völkerrecht, 3 y ss. ( $2^{\mathrm{a}}$ ed., C. F. Müller Verlag, Heidelberg, 2004).

39 Knut Ipsen, Völkerrecht, 7 ss. (C. H. Beck, München, 2004).

40 Knut Ipsen, Völkerrecht, 8 (C. H. Beck, München, 2004).

41 Corte Permanente de Justicia Internacional, CPJI, Sentencia caso Lotus, Asunto del Vapor, Lotus, Francia contra Turquía, Serie A 10, Sentencia de 7 septiembre de 1927, 8. Disponible en: http://www.icj-cij.org/pcij/serie_A/A_10/30_Lotus_Arret.pdf, http://www.icj-cij.org/pcij/ serie_other/cpji-pcij.pdf. Jaume Ferrer-Lloret, La insoportable levedad del Derecho internacional consuetudinario en la jurisprudencia de la Corte Internacional de Justicia: el caso de las inmunidades jurisdiccionales del Estado, 24 Revista Electrónica de Estudios Internacionales, REEI, Asociación Española de Profesores de Derecho Internacional y Relaciones Internacionales, AEPDIRI, 1-36, 4 ss. (2012). Disponible en: http://www.reei.org/index.php/revista/num24/ articulos/insoportable-levedad-derecho-internacional-consuetudinario-jurisprudencia-corteinternacional-justicia-caso-inmunidades-jurisdiccionales-estado 
yendo esa subjetividad internacional. Así, crean organizaciones internacionales, o atribuyen al individuo subjetividad parcial en ámbitos limitados y según acuerdos.

El destacado jurista alemán Karl Siegfried Döhring sostiene que el consenso no es satisfactorio como fundamento del DIP y se pregunta ¿por qué el acuerdo obliga $?^{42}$ Cuestiona que el consabido y manido pacta sunt servanda sea una norma vinculante. Continúa señalando que el postulado de que la vida en común nos exige o hace necesario ese acuerdo, tampoco es satisfactorio, ya que significaría previamente asumir que esa vida en común es necesaria y al tender naturalmente a ella, es necesario regularla jurídicamente, fundamentando su valor en el acuerdo requerido para que esa "necesaria” vida en común se desarrolle. Un círculo virtuoso, pero improbable si no es posible demostrar la necesidad natural de vida en común. Para Döhring, lo que fundamenta el DIP es lo que denomina Empirie, es decir, la realidad que nos muestra la existencia de una norma respetada como jurídica por los sujetos de DIP.

Considerar la realidad como elemento de análisis para sostener que el DIP es derecho, parece un punto de partida acertado, y precisamente desde ahí se inicia el análisis de este trabajo. Pero es el punto de donde se parte para poder buscar el porqué, en realidad, estas normas se cumplen como jurídicas. A diferencia de Döhring, sostenemos que es precisamente esa tendencia que se aprecia - prácticamente sin excepción en la historia de la humanidad-, la de vivir en comunidad, la que sirve de base para encontrar el fundamento del DIP. Sin embargo, como antecedente remoto, no es la necesidad de vida en común lo que funda el DIP, no es ella la que otorga naturaleza jurídica a esas normas. Son más bien el carácter y la naturaleza que los grupos humanos atribuyen al acuerdo sostenido con otros grupos, sobre temas de interés común en los cuales reconocen la necesidad de interactuar, entregando a esos acuerdos certeza de cumplimiento mediante la atribución de juridicidad, es decir,

42 Karl Döhring, Völkerrecht, 4 ss. (2 ${ }^{\mathrm{a}}$ ed., C. F. Müller Verlag, Heidelberg, 2004). 
de consecuencias jurídicas en caso de incumplimiento. Ahora bien, la diversidad cultural, económica, histórica, etc. de los grupos humanos políticamente organizados en un territorio, impide que la naturaleza jurídica de esos acuerdos sea otra que el acuerdo señalado de entregar naturaleza jurídica. El pacta sunt servanda lo entendemos entonces como un postulado de garantía de cumplimiento, creado por los sujetos de DIP, que permite consensuar acuerdos con carácter jurídico. Las normas creadas bajo ese postulado, reconocidas así por los sujetos intervinientes, tienen naturaleza jurídica, y por tanto vinculan y obligan a su cumplimiento jurídico. Y esto se dará en aquellas normas así concebidas y para aquellos casos en que el consentimiento haya formado acuerdo con otro y en los términos y límites de ese acuerdo. El pacta sunt servanda es el equivalente al contrato social entre los miembros de una comunidad nacional. En el caso de la interacción de grupos humanos políticamente organizados en territorios, y que acuerdan generar vínculos exigibles jurídicamente. El "contrato" poco más puede decir que: "aquello que hemos pactado nos obliga jurídicamente a su cumplimiento". Son tan diversos los grupos humanos que no hay una opción diferente. Ellos decidirán a qué otras manifestaciones o entidades les otorgan el derecho de usar el pacta sunt servanda. Son ellos en definitiva los que actúan, interactúan y definen normas y contenidos ${ }^{43}$.

Ahora bien, radicado el fundamento de validez en el consenso, no por eso es inevitable llegar a la conclusión de que es una obra vacía en contenido, y solo derivada de aquello que los estados actualmente quieran disponer y, por ende, consensuar. El presente trabajo no plantea una repostulación disfrazada del positivismo más ortodoxo. Esto, porque una perspectiva del contenido de las normas del DIP nos lleva a una necesaria conclusión: hay valores que los estados están dispuestos a proteger jurídicamente. Al menos, podemos mencionar el consenso casi unánime que

43 Hans-Joachim Cremer, Völkerrecht - Alles nur Rhetorik?, 67 Zeitschrift für ausländisches öffentliches Recht und Völkerrecht, ZaöRV,267-296, 286 ss. (2007). Disponible en: http://www. zaoerv.de/67_2007/67_2007_2_267_296.pdf, http://www.zaoerv.de/67_2007/vol67.cfm 
concita el valor de la $\mathrm{paz}^{44}$. Así mismo, los derechos humanos. Sin embargo, en esto, es necesario indicar que el compromiso es diferenciado, lo que se aprecia en la legitimación activa entregada a los individuos para accionar en instancias internacionales en contra de los estados que violan estos derechos humanos. También es demostrativo de la diferenciada escala de compromiso que los estados están dispuestos a asumir (aceptar, consensuar, obligarse) en relación con el estado de ratificaciones que en el ámbito universal, tienen los protocolos a los convenios que otorgan recurso individual y que abandonan a la mera obligación de informes y seguimientos de recomendaciones que imponen los tratados originales ${ }^{45}$. Esta sociedad internacional, y utilizando palabras de Luis Recasens-Siches ${ }^{46}$, crea un derecho no aleatorio, sino basado en valores. La idea del mencionado autor es útil para

44 La ratificación de la Carta de la ONU da prueba de ello, siendo su principal función el mantenimiento de la paz y la seguridad. Organización de Naciones Unidas, ONU, Carta de las Naciones Unidas, San Francisco, 26 de junio de 1945. Disponible en: http://www.un.org/es/ charter-united-nations/, https://treaties.un.org/Pages/ViewDetails.aspx?src=TREATY\&mtdsg_ no=I-1\&chapter=1\&clang=_en

45 Organización de Naciones Ūnidas, ONU, Pacto Internacional de Derechos Civiles y Políticos, adoptado y abierto a la firma, ratificación y adhesión por la Asamblea General en su resolución 2200 A (XXI), 16 de diciembre de 1966. Disponible en: http://www.ohchr.org/SP/Professional Interest/Pages/CCPR.aspx. Organización de Naciones Unidas, ONU, Pacto Internacional de Derechos Económicos, Sociales y Culturales, adoptado y abierto a la firma, ratificación y adhesión por la Asamblea General en su resolución 2200 A (XXI), 16 de diciembre de 1966. Disponible en: http://www.ohchr.org/SP/ProfessionalInterest/Pages/CESCR.aspx. Organización de Naciones Unidas, ONU, Convención sobre la Eliminación de Todas las Formas de Discriminación contra la Mujer, adoptada y abierta a la firma y ratificación, o adhesión, por la Asamblea General en su resolución 34/180, de 18 de diciembre de 1979. Disponible en: http://www.ohchr. org/SP/ProfessionalInterest/Pages/CEDAW.aspx. Organización de Naciones Unidas, ONU, Convención sobre los Derechos del Niño, adoptada y abierta a la firma y ratificación por la Asamblea General en su resolución 44/25, Nueva York, 20 de noviembre de 1989. Disponible en: http://www.ohchr.org/SP/ProfessionalInterest/Pages/CRC.aspx. Organización de Naciones Unidas, ONU, Protocolo Facultativo de la Convención sobre los Derechos del Niño relativo a la Participación de Niños en los Conflictos Armados, Asamblea General, Resolución A/ RES/54/263, 25 de mayo de 2000. Disponible en: http://www.ohchr.org/SP/ProfessionalInterest/ Pages/OPACCRC.aspx. Organización de Naciones Unidas, ONU, Protocolo Facultativo de la Convención sobre los Derechos del Niño relativo a la Venta de Niños, la Prostitución Infantil y la Utilización de Niños en la Pornografía, 25 de mayo de 2000. Disponible en: http://www. unicef.org/spanish/specialsession/documentation/documents/op_se_sp.pdf. Organización de Naciones Unidas, ONU, Protocolo Facultativo de la Convención sobre los Derechos del Niño relativo a un Procedimiento de Comunicaciones, Asamblea General, Resolución A/RES/66/138, 19 de diciembre de 2011. Disponible en: https://treaties.un.org/doc/source/signature/2012/a-res66-138-spanish.pdf

46 Luis Recasens-Siches, Tratado general de filosofía del derecho, 368 (4ª ed., Porrúa, México, 1975). La utilización de la idea no significa adherir en este trabajo a la teoría del mencionado autor. 
graficar que el DIP no es un sistema jurídico, ordenamiento o cúmulo de normas derivado del consenso de los sujetos de DIP y que se ha ido conformando como un vacío conjunto de normas jurídicas sin valores o que en él quepa cualquiera. Lentamente, la sociedad internacional organizada jurídicamente en normas con distinto número de vinculados, según sean el instrumento o la fuente de los que hablamos, se ha ido articulando en función de determinados valores.

Siguiendo nuestra hipótesis, se analizará ahora si hay una supuesta constitución internacional. Y cuál sería su contenido.

\section{Constitución DEL Derecho InTERnACIONAL}

La constitucionalización del DIP es un tema actual, tratado en la doctrina ${ }^{47}$. La existencia de la discusión da cuenta de un intento de reconocimiento de que el DIP ha permeado de tal forma las relaciones internacionales que la sociedad internacional mostraría indicios inequívocos de regularse jurídicamente desde una norma fundamental. El calificativo o la utilización del concepto constitución dan cuenta de la drasticidad de la corriente, ya que no se ha creado un concepto para una norma fundamental del propio DIP que recoja su particular naturaleza, sino que se ha extraído un concepto desde el derecho nacional que cumple funciones fundantes de la sociedad nacional. Esto solo puede ser intencional y no una falta de creatividad. El concepto constitucionalización del DIP - o una constitución de él- es por lo demás atractivo pero enigmático, en palabras de Matthias Knauff ${ }^{48}$.

47 Stefan Kadelbach, Völkerrecht als Verfassungsordnung? Zur Völkerrechtswissenschaft in Deutschland, 67 Zeitschrift für ausländisches öffentliches Recht und Völkerrecht, ZaöRV, 599621, 609, 620 (2007). Disponible en: http://www.zaoerv.de/67_2007/67_2007_3_a_599_622. pdf. Jürgen Habermas, Die Krise der Europäischen Union im Lichte einer Konstitutionalisierung des Völkerrecht - Ein Essay zur Verfassung Europas, 72 Zeitschrift für ausländisches öffentliches Recht und Völkerrecht, ZaöRV, 1-44, 1 (2012). Disponible en: http://www.zaoerv. de/72_2012/72_2012_1_a_1_44.pdf

48 Según Matthias Knauff, va desde aspectos de jerarquía normativa, hasta simples tendencias jurídicas. Referencias a las distintas concepciones del DIP y sus representantes en Matthias Knauff, Konstitutionalisierung im inner - und überstaatlichen Recht- Konvergenz oder Divergenz, 68 Zeitschrift für ausländisches öffentliches Recht und Völkerrecht, ZaöRV, 453-490, 
Siendo así, es imposible que se aborde sin ver previamente el fundamento de validez. Habiendo intentado exponer precedentemente un fundamento de validez para el DIP, se intentará analizar ahora si en ese contexto teórico, es posible hablar de una constitucionalización del DIP o una constitución de él.

Primero, debemos señalar que el traslado conceptual de una órbita jurídica como el derecho nacional a otra, como el DIP, presenta dificultades de inicio. A continuación, se analizará la posible existencia de una constitución internacional, y cuál será esta, o si bien es una constitucionalización del DIP.

\section{A. Constitución del Derecho Internacional Público}

Una constitución de derecho internacional implica la referencia a una norma determinada, independiente de la fuente jurídica que la contenga. Otorga seguridad jurídica al entregar una estructura política y jurídica, órganos, procesos de creación de normas, derechos y deberes, formas de gobierno, etc. ${ }^{49}$. Refleja un estado de derecho ${ }^{50}$. Además contiene un êthos emanado del conjunto de individuos que regula, aquello que diferencia cultural y socialmente a ese estado de otro. Esto, sin embargo, en el marco de una constitución que responde a parámetros de estado de derecho, y no que se limite solo a ser una norma fundamental reguladora de estructuras políticas. Si consideramos la constitución como lo primero, es necesario saber si hay alguna norma del DIP de la que se prediquen estas características y, por ende, se manifieste como una constitución internacional.

455, 457 ss. (2008). Disponible en: http://www.zaoerv.de/68_2008/68_2008_2_a_453_490.pdf. Ver también Jean-Denis Mouton, L'identité constitutionnēlle, un concept pertinent au regard du droit international?, 118 Revue générale de droit international public, RGDIP, 3, 501-515, 510 ss. (2014).

49 Los elementos distintivos de una constitución, en Isabelle Ley, Kant versus Locke: Europarechtlicher und Völkerrechtlicher Konstitutionalismus im Vergleich, 69 Zeitschrift für ausländisches öffentliches Recht und Völkerrecht, ZaöRV, 317-345, 331-340 (2009). Disponible en: http://www. zaoerv.de/69_2009/69_2009_2_a_317_346.pdf

50 Philip Kunig, Der Rechtsstaat, en Festschrift 50 Jahre Bundesverfassungsgericht, 2 Band: Klärung und Fortbildung des Verfassungsrechts, 421-444, 425 ss. (Peter Badura \& Horst Dreier, hrsg., Mohr Siebeck, Tübingen, 2001). 
Se menciona recurrentemente la Carta de Naciones Unidas ${ }^{51}$. Diversos autores sostienen que ella es una verdadera constitución del DIP contemporáneo ${ }^{52}$, mientras que otros niegan siquiera su posibilidad de existir ${ }^{53}$. Para autores como Francisco OrregoVicuña, la constitución si bien es una "permanente aspiración de la sociedad internacional" 54 , la identificación de sus valores cambia y por lo tanto sigue siendo un "proceso controlado de limitación de la soberanía" $" 55$. Otros - como Christian Tomuschat - perciben una suerte de constitucionalización en el artículo 103 de la Carta, no así una constitución ${ }^{56}$.

La Carta de Naciones Unidas contiene el bien jurídico en torno al cual despliega sus funciones. Este bien es la paz y la seguridad mundial, contenido en el artículo 1 del tratado ${ }^{57}$. La

51 Firmada el 26 de junio de 1945, en San Francisco, entró en vigencia el 24 de octubre de 1945. Estado de ratificaciones: http://www.un.org/es/member-states/. Bardo Fassbender, The United Nations Charter as Constitution of the International Community, 36 Columbia Journal of Transnational Law, 529-619 (1998). Disponible en: https://www.alexandria.unisg.ch/234620/. Hermann Mosler, Völkerrecht als Rechtsordnung, 36 Zeitschrift für ausländisches öffentliches Recht und Völkerrecht, ZaöRV, 6-49, 31 ss. (1976). Disponible en: http://www.zaoerv. de/36_1976/36_1976_1_3_a_6_49.pdf

52 Karl Döhring, $\overline{\text { Völkerrecht }}, \overline{7}$ ss. (2 ${ }^{\mathrm{a}}$ ed., C. F. Müller Verlag, Heidelberg, 2004).

53 Stefan Kadelbach sostiene que la tesis de la constitucionalización se topa con críticas referidas a la soberanía, y legitimidad de las organizaciones internacionales, IO. Stefan Kadelbach, Völkerrecht als Verfassungsordnung? Zur Völkerrechtswissenschaft in Deutschland, 67 Zeitschrift für ausländisches öffentliches Recht und Völkerrecht, ZaöRV, 599-621, 610 (2007). Disponible en: http://www.zaoerv.de/67_2007/67_2007_3_a_599_622.pdf

54 Francisco Orrego-Vicuña, El derecho internacional: entre el cambio y la disolución, 39 Revista de Estudios Internacionales de la Universidad de Chile, 54, 57-66, 62 (2006). Disponible en: http://www.revistaei.uchile.cl/index.php/REI/article/viewPDFInterstitial/14471/14784

55 Francisco Orrego-Vicuña, El derecho internacional: entre el cambio y la disolución, 39 Revista de Estudios Internacionales de la Universidad de Chile, 54, 57-66, 62 (2006). Disponible en: http://www.revistaei.uchile.cl/index.php/REI/article/viewPDFInterstitial/14471/14784

56 Christian Tomuschat, International Law as a Coherent System: Unity or Fragmentation?, en Looking to the Future: Essays on International Law in Honor of W. Michael Reisman, Chapter 18, 323-354, 336 ss. (Mahnoush H. Arsanjani, Jacob Katz Cogan, Robert D. Sloane \& Siegfried Wiessner, eds., Martinus Nijhoff Publishers, Boston, 2011).

57 Artículo 1. Los propósitos de las Naciones Unidas son: 1. Mantener la paz y la seguridad internacionales, y con tal fin: tomar medidas colectivas eficaces para prevenir y eliminar amenazas a la paz, y para suprimir actos de agresión u otros quebrantamientos de la paz; y lograr por medios pacíficos, y de conformidad con los principios de la justicia y del derecho internacional, el ajuste o arreglo de controversias o situaciones internacionales susceptibles de conducir a quebrantamientos de la paz. 2. Fomentar entre las naciones relaciones de amistad basadas en el respeto al principio de la igualdad de derechos y al de la libre determinación de los pueblos, y tomar otras medidas adecuadas para fortalecer la paz universal. 3. Realizar la cooperación internacional en la solución de problemas internacionales de carácter económico, social, cultural o humanitario, y en el desarrollo y estímulo del respeto a los derechos humanos y a las libertades fundamentales de todos, sin hacer distinción por motivos de raza, sexo, idioma o religión. Y 4. Servir de centro que armonice los esfuerzos de las naciones por alcanzar estos 
naturaleza de este bien jurídico requiere la universalidad en la conformación de la organización. Incluso, al redactar la Carta, los estados aspiran a que la organización sea capaz de conducir el comportamiento de los estados no miembros, de acuerdo a los principios contenidos en ella ${ }^{58}$, respetando sin embargo para todos los asuntos de carácter interno ${ }^{59}$.

Si consideramos la Carta como una constitución, debiéramos concluir que comulga con alguna de las funciones propias de una norma fundamental de carácter constitucional. Entre las normas de la Carta establecidas con carácter imperativo, encontramos los artículos 1, 2 y 103. Que contienen diversas obligaciones, principios y propósitos.

El artículo 103 entrega un rango jerárquico en relación con otras normas del sistema jurídico internacional al sostener que:

En caso de conflicto entre las obligaciones contraídas por los Miembros de las Naciones Unidas en virtud de la presente Carta y sus obligaciones contraídas en virtud de cualquier otro convenio internacional, prevalecerán las obligaciones impuestas por la presente Carta.

Este artículo dota de jerarquía indiscutible a las normas de la Carta en relación con otros acuerdos internacionales celebrados entre estados. Lo que esta norma no hace es establecer un orden jerárquico en relación con el derecho nacional, aquel emitido por actos unilaterales de los estados con efectos internos, es decir, su derecho.

Coordinado con el capítulo VII ${ }^{60}$, el artículo 1 de la Carta señala obligaciones de comportamiento de los estados en relación

propósitos comunes.

58 Artículo 2. Para la realización de los Propósitos consignados en el Artículo 1, la Organización y sus Miembros procederán de acuerdo con los siguientes Principios: 6. La Organización hará que los Estados que no son Miembros de las Naciones Unidas se conduzcan de acuerdo con estos Principios en la medida que sea necesaria para mantener la paz y la seguridad internacionales.

59 Artículo 2. Para la realización de los Propósitos consignados en el Artículo 1, la Organización y sus Miembros procederán de acuerdo con los siguientes Principios: 7. Ninguna disposición de esta Carta autorizará a las Naciones Unidas a intervenir en los asuntos que son esencialmente de la jurisdicción interna de los Estados, ni obligará; a los Miembros a someter dichos asuntos a procedimientos de arreglo conforme a la presente Carta; pero este principio no se opone a la aplicación de las medidas coercitivas prescritas en el Capítulo VII.

60 El que establece el monopolio del uso de la fuerza radicado en el Consejo de Seguridad y el derecho a la legítima defensa. 
con la solución pacífica de las controversias internacionales, que completan y complementan los derechos y obligaciones que los estados deben observar en sus relaciones internacionales. Es decir, podríamos sostener que el artículo 103 entrega supremacía a sus normas en relación con los acuerdos a que lleguen los estados relativos al objetivo fundamental de la organización: mantenimiento de la paz y la seguridad internacionales. ¿Basta eso para señalar que la Carta es una Constitución? Parece más bien el establecimiento normativamente coherente de un articulado de normas jurídicas internacionales, que no permiten formas de solución anexas a las pactadas en la Carta, esto es, pacíficas.

Esto lo refuerza un claro artículo $2^{61}$ que, basado en la igualdad soberana de los estados y en el principio de no intervención, reafirma la obligación del mantenimiento de la paz. El número 7 del mencionado artículo señala que los asuntos internos son de exclusiva decisión de los estados, sin perjuicio a que den lugar a la aplicación del Capítulo VII (medidas coercitivas impuestas por el Consejo de Seguridad). Es imposible no relacionar este numeral del artículo 2 con el artículo $55^{62}$ que, partiendo del supuesto de

61 Artículo 2. Para la realización de los Propósitos consignados en el Artículo 1, la Organización y sus Miembros procederán de acuerdo con los siguientes Principios: 1. La Organización está basada en el principio de la igualdad soberana de todos sus Miembros. 2. Los Miembros de la Organización, a fin de asegurarse los derechos y beneficios inherentes a su condición de tales, cumplirán de buena fe las obligaciones contraídas por ellos de conformidad con esta Carta. 3. Los Miembros de la Organización arreglarán sus controversias internacionales por medios pacíficos de tal manera que no se pongan en peligro ni la paz y la seguridad internacionales ni la justicia. 4. Los Miembros de la Organización, en sus relaciones internacionales, se abstendrán de recurrir a la amenaza o al uso de la fuerza contra la integridad territorial o la independencia política de cualquier Estado, o en cualquier otra forma incompatible con los Propósitos de las Naciones Unidas. 5. Los Miembros de la Organización prestarán a esta toda clase de ayuda en cualquier acción que ejerza de conformidad con esta Carta, y se abstendrán de dar ayuda a Estado alguno contra el cual la Organización estuviere ejerciendo acción preventiva o coercitiva. 6. La Organización hará que los Estados que no son Miembros de las Naciones Unidas se conduzcan de acuerdo con estos Principios en la medida que sea necesaria para mantener la paz y la seguridad internacionales. 7. Ninguna disposición de esta Carta autorizará a las Naciones Unidas a intervenir en los asuntos que son esencialmente de la jurisdicción interna de los Estados, ni obligará; a los Miembros a someter dichos asuntos a procedimientos de arreglo conforme a la presente Carta; pero este principio no se opone a la aplicación de las medidas coercitivas prescritas en el Capítulo VII.

62 Con el propósito de crear las condiciones de estabilidad y bienestar necesarias para las relaciones pacíficas y amistosas entre las naciones, basadas en el respeto al principio de la igualdad de derechos y al de la libre determinación de los pueblos, la Organización promoverá: a. niveles de vida más elevados, trabajo permanente para todos, y condiciones de progreso y desarrollo económico y social. b. La solución de problemas internacionales de carácter económico, social 
la igualdad soberana y la libre determinación de los pueblos, señala aquello que la organización debe promover. De esta obligación para la organización relacionada con la promoción de condiciones sociales, económicas, de salud y el respeto a los derechos humanos, han derivado diversos tratados internacionales con diversas fórmulas de fiscalización y cumplimiento. Y con diversos grados además de estado de ratificaciones, ya que no son normas secundarias vinculantes desde su formulación, sino que como todo tratado, deben ser ratificadas.

Si sumamos estos elementos, tenemos una organización creada por estados, que se autoimponen una obligación exigible jurídicamente desde el momento del ingreso a la ONU: mantener la paz y la seguridad en las relaciones internacionales, absteniéndose del uso de la fuerza. En relación con los otros objetivos derivados de la organización y de su deber de promoción, la organización está sujeta a la labor generadora de tratados o establecimiento de otras fuentes jurídicas aplicables ${ }^{63}$.

Por otro lado, no podemos dejar de mencionar las normas de la Carta sobre la membrecía a la institución. Es voluntario ratificar la Carta. Pero dado el hecho de que prácticamente todos los estados la han ratificado, nos queda apreciar si es posible denunciar la Carta y, por ende, retirarse de la ONU. La Carta no contiene norma expresa al respecto. La Convención de Viena sobre el Derecho de los Tratados en su artículo 56 dispone:

1. Un tratado que no contenga disposiciones sobre su terminación ni prevea la denuncia o el retiro del mismo, no podrá ser objeto de denuncia o de retiro a menos:

a) que conste que fue intención de las partes admitir la posibilidad de denuncia o de retiro: $o$

b) que el derecho de denuncia o de retiro pueda inferirse de la naturaleza del tratado.

y sanitario, y de otros problemas conexos; y la cooperación internacional en el orden cultural y educativo. Y c. el respeto universal a los derechos humanos y a las libertades fundamentales de todos, sin hacer distinción por motivos de raza, sexo, idioma o religión, y la efectividad de tales derechos y libertades.

63 La paulatina generación de nuevas normas y su aceptación como normas jurídicas debe ser permanentemente apreciada. Así actúa la ONU en lo que se ha definido como obligación de proteger. 
2. Una parte deberánotificar con doce meses, por lo menos, de antelación su intención de denunciar un tratado o de retirarse de él conforme al párrafo 1.

Sin embargo, en 1965 y a propósito de que Malasia ingresó como miembro no permanente al Consejo de Seguridad, Indonesia presentó su retiro de la Organización, sin mediar reacción alguna de la ONU 64 .

Sumado a esto, el artículo 6 de la Carta sostiene:

Todo Miembro de las Naciones Unidas que haya violado repetidamente los Principios contenidos en esta Carta podrá ser expulsado de la Organización por la Asamblea General a recomendación del Consejo de Seguridad.

Cuesta explicarse que un miembro se retire del tratado, como de hecho sucedió, y que quede al margen de una constitución internacional, o que la propia organización lo expulse. Salvo que esta sea una norma que tenga otro carácter y no el de una constitución de las características que se le pretende atribuir.

Más que una constitución, habría una norma jurídica cuyo objetivo principal impone una condición de relación entre los estados con la que comulga la mayoría de los estados: abstención del uso de la fuerza en la solución de controversias internacionales. Esta norma se dota de un sistema eficaz de exigencia en el cumplimiento, a la luz de las medidas posibles de adoptar de acuerdo al capítulo VII de la Carta.

\section{B. Constitucionalización del DIP}

Excluida la constitución internacional, queda plantearse el concepto de constitucionalización, vago y complejo de abordar.

El DIP conoce en la actualidad normas jurídicas que protegen bienes jurídicos determinados. La adscripción a ellos y por tanto la sujeción a las obligaciones que conllevan, dependen de la participación de los estados en esas normas, manifestada

64 Sobre la posibilidad de retiro, Ignaz Seidl-Hohenveldern, Das Recht der Internationalen Organisationen einschließlich der Supranationalen Gemeinschaften, 80 ss. ( $7^{\mathrm{a}}$ ed., Carl Heymann Verlag, Köln, Berlin, Bonn, München, 2000). 
mediante el consentimiento. Las excepciones son la norma del artículo 2 numeral 6 de la Carta ya mencionada y las normas de ius cogens ${ }^{65}$. En relación con estos últimos, sabemos que corresponden a algunas normas, pocas, respecto de las que hay consenso: prohibición del uso de la fuerza (su marco normativo es el artículo 1 número 2 de la Carta), y algunos derechos humanos: desaparición forzada de personas, genocidio, esclavitud, tortura, trata de personas.

Considerando el número significativamente alto de tratados y estados involucrados en diversos instrumentos, y la disposición de la soberanía en relación con el uso de la fuerza, podemos sostener que hay un êthos entre la mayoría de los estados de la sociedad internacional que, por un lado, implica la relación pacífica entre ellos, pero además, algunos valores que trasuntan un interés común y que tienen relación con la protección de la persona humana ${ }^{66}$, desplegándose una multitud de fuentes jurídicas universales, regionales, etc., sobre los más diversos aspectos de los derechos humanos. Tratándose de fuentes convencionales, ellas presentan variados sistemas de control y participación de los distintos estados. Ahora bien, la prohibición del uso de la fuerza y los derechos humanos no son las únicas temáticas que se aprecian como recurrentes y más extendidas en su regulación. Hay otros temas, como el derecho del comercio internacional. La cantidad de tratados en este ámbito, el número de países involucrados, la dispar profundidad en que algunos se relacionan con otros según mayores o menores grados de acercamiento en sus relaciones, la cantidad de miembros que tiene la Organización Mundial del Comercio, $\mathrm{OMC}^{67}$, cuyo objetivo es la apertura

\footnotetext{
65 Excepción aparente cuyo análisis se dejará para un estudio posterior. Un análisis exhaustivo sobre el tema se encuentra en Stefan Kadelbach, Jus cogens, obligations Erga Omnes and Other Rules - The Identification of Fundamental Norms, en The Fundamental Rules of the International Legal Order, Jus Cogens and Obligations Erga Omnes, 21-40 (Christian Tomuschat \& Jean-Marc Thouvenin, eds., Martinus Nijhoff Publishers, Leiden, Boston, 2006).

66 Isabelle Ley sostiene que el actual DIP se trataría de un derecho cuyo centro parece estar en la persona, más que en la soberanía. Isabelle Ley, Kant versus Locke: Europarechtlicher und Völkerrechtlicher Konstitutionalismus im Vergleich, 69 Zeitschrift für ausländisches öffentliches Recht und Völkerrecht, ZaöRV,317-345, 330 ss. (2009). Disponible en: http://www.zaoerv. de/69_2009/69_2009_2_a_317_346.pdf.

67 https://www.wto.org/english/thewto_e/whatis_e/tif_e/org6_e.htm
} 
del comercio, nos permiten decir que la sociedad internacional actual comulga de valores y bienes jurídicos. Estos temas, sin embargo, tienen diversas formas de promoción y protección, como ya se señaló. Pero no es posible ignorar que los grandes temas entre los estados se regulan jurídicamente de forma más profusa. Ahora bien, salvo la prohibición del uso de la fuerza, que tiene no solo contenido normativo claro, sino que además una eficacia de cumplimiento garantizada por un Capítulo VII de la Carta (mediante el ejercicio de las funciones de un órgano de dudosa democracia interna), los otros temas son tratados en diversos instrumentos, no tienen igual exigibilidad compulsiva y dependen de las instancias creadas por los estados. En el caso de los derechos humanos, dependen de concepciones nacionales para llenar de contenido los derechos; en el caso del comercio, los grados de "apertura" dependen de opciones nacionales.

Los diversos caminos nacionales son evidentes en todo ámbito, menos en el de la prohibición del uso de la fuerza. No por nada los estados no han generado instancias jurisdiccionales en torno a los tratados de derechos humanos nacidos en el seno de la ONU. No por nada las instancias internacionales existentes en esa materia tienen competencias asociadas a la ratificación de protocolos anexos y sin constituirse como instancias judiciales, o de las existentes, solo una, el Tribunal Europeo de Derechos Humanos, TEDH, tiene un recurso individual obligatorio derivado inmediatamente de la ratificación del Convenio para la Protección de los Derechos Humanos y de las Libertades Fundamentales ${ }^{68}$. No por nada la "apertura comercial" genera conflictos en las sociedades nacionales y tensiona las políticas adoptadas en algunos estados. Y no por nada, los grados de esa "apertura" son disímiles.

La globalización permite apreciar dos cosas: por un lado, efectivamente, hay valores y bienes jurídicos que los estados

68 Consejo de Europa, Convenio para la Protección de los Derechos Humanos y de las Libertades Fundamentales, Roma, 4 de noviembre de 1950, modificado por los Protocolos 11 y 14, completado por el Protocolo adicional y los Protocolos 4, 6, 7, 12 y 13. Disponible en: http://www. echr.coe.int/Documents/Convention_SPA.pdf 
tienen interés por proteger y cuidar, mediante la creación de normas jurídicas internacionales. Y por otro, esta misma globalización permite constatar profundas diferencias en las formas de llevarlas adelante ${ }^{69}$. Si, como vimos, no hay opción de una constitución internacional en los términos que se le pretende dar por ejemplo a la Carta de la ONU, ¿es posible hablar de una "constitucionalización" del DIP? La convicción de la protección de los derechos humanos, el aparente valor de la "apertura del comercio internacional" y la prohibición del uso de la fuerza para resolver conflictos internacionales constituirían un trasfondo valórico que impregna lo jurídico ${ }^{70}$. No hay duda de que existe un principio de comunidad ética ${ }^{71}$ que mediante la voluntad de los estados ha ido adquiriendo contenido jurídico. Si a esto se le denomina constitucionalización, el término es errado. Todo esto plantea una comunidad de ciertos valores respecto de los cuales los estados han emprendido el camino de la regulación jurídica. Mientras ese camino sea aún — salvo en la prohibición del uso de la fuerza - un espectro de normas con diferentes formas de fiscalización y comunión, se trata más bien de la paulatina creación de una comunidad valórica.

69 Andreas L. Paulus señala que la globalización es al parecer una traba a la constitucionalización del DIP. Andreas L. Paulus, Zur Zukunft der Völkerrechtswissenschaft in Deutschland: Zwischen Konstitutionalisierung und Fragmentierung des Völkerrechts, 67 Zeitschrift für ausländisches öffentliches Recht und Völkerrecht, ZaöRV, 695-720, 697 (2007). Disponible en: http://www.zaoerv.de/67_2007/67_2007_3_a_695_720.pdf. Anne Peters sostiene que es el método científico el que - obligado por la globalización- requiere una revisión. Anne Peters, Die Zukunft der Völkerrechtswissenschaft: Wider den epistemischen Nationalismus, 67 Zeitschrift für ausländisches öffentliches Recht und Völkerrecht, ZaöRV, 721-776, 775 (2007). Disponible en: http://www.zaoerv.de/67_2007/67_2007_3_a_721_776.pdf

70 Andreas Fischer-Lescano sostiene que la constatación $\bar{d}$ e valores comunes es el principio de una posible regulación común. Andreas Fischer-Lescano, Die Emergenz der Globalverfassung, 63 Zeitschrift für ausländisches öffentliches Recht und Völkerrecht, ZaöRV, 717-760 (2003). Disponible en: http://www.zaoerv.de/63_2003/63_2003_3_a_717_760.pdf

71 Andreas L. Paulus, Zur Zukunft der V̈̈lkerrechtswissenschaft in Deutschland: Zwischen Konstitutionalisierung und Fragmentierung des Völkerrechts, 67 Zeitschrift für ausländisches öffentliches Recht und Völkerrecht, ZaöRV, 695-720, 700 (2007). Disponible en: http://www. zaoerv.de/67_2007/67_2007_3_a_695_720.pdf 
Conclusiones

Considerando el consentimiento como fundamento de validez para el derecho internacional, considerando además el contenido de las normas jurídicas y los distintos grados de vinculación entre los estados y mecanismos diversos de fiscalización, podemos sostener que hay algo de común que subyace al DIP. Este contenido común que ha confluido en la sociedad — por interés de los estados, que por actos de voluntad lo han plasmado en diversas fuentes normativas - son valores y bienes jurídicos que impregnan el DIP. Sumado a esto, no es posible sin embargo soslayar que la existencia de estos valores comunes en términos de constitucionalización o constitución es una discusión que ha tenido como centro geográfico mayoritario el estadounidense y el europeo ${ }^{72}$. En ese contexto, parece más bien una discusión que, en ese marco, atañe a Occidente. La existencia de valores comunes es real y el centro del interés de una gran cantidad de estados se ha volcado en valores que tienen como eje al individuo $^{73}$. Pero si esto es una constitución o una constitucionalización del DIP es una discusión occidental y, por lo tanto, no verdaderamente de la $\mathrm{SI}^{74}$.

Hay una confluencia consistente de valores entre los estados, que en determinados ámbitos los guía en sus relaciones jurídi-

72 Andreas L. Paulus, Zur Zukunft der Völkerrechtswissenschaft in Deutschland: Zwischen Konstitutionalisierung und Fragmentierung des Völkerrechts, 67 Zeitschrift für ausländisches öffentliches Recht und Völkerrecht, ZaöRV, 695-720, 703 (2007). Disponible en: http://www. zaoerv.de/67_2007/67_2007_3_a_695_720.pdf

73 Esto no se limita a los derechos humanos. Abarca el comercio internacional y las ventajas asociadas para los individuos, y la paz y seguridad, que tienen una arista de conveniencia e interés tanto para el individuo como para el estado mismo considerado como político y diverso de sus habitantes. Isabelle Ley, Kant versus Locke: Europarechtlicher und Völkerrechtlicher Konstitutionalismus im Vergleich, 69 Zeitschrift für ausländisches öffentliches Recht und Völkerrecht, ZaöRV, 317-345, 330 ss. (2009). Disponible en: http://www.zaoerv. de/69_2009/69_2009_2_a_317_346.pdf

74 Por lo demás, los recientes sucesos en torno a la salida del Reino Unido de la Unión Europea dan cuenta de que incluso ahí donde se creía ver y se discutía la existencia de una constitución, hay quiebres. Sin poder prever el curso doctrinario que tomará la discusión sobre el Brexit, es posible adelantar una ardua discusión sobre la "constitución europea" en peligro. Pero sin dejarse llevar por emociones, el Reino Unido seguirá adhiriendo a los valores y protegiendo los bienes jurídicos que son comunes: paz, seguridad, derechos humanos. La forma y los procesos no son necesariamente mediante tratados con aspiración de constituciones según conceptos nacionales. 
cas. Sin embargo, un cúmulo asentado de valores plasmados en normas jurídicas acordadas no es suficiente para constatar la creación de una constitución internacional. Y en cuanto a la constitucionalización, si la consideramos como un camino hacia la generación de una constitución, es una perspectiva sin pruebas de concretarse mientras no incluya otros actores y autores que representen la SI en su conjunto. Si esos valores se consideran un êthos de la comunidad internacional, no es necesario el nombre constitucionalización. Bastaría señalar que son los valores subyacentes al DIP, cuya eficacia y cumplimiento aún dependen de los grados de compromiso, vinculación y disposición de los estados. 


\section{BIBLIOGRAFÍA}

\section{Libros}

Barbé, Esther, Relaciones internacionales ( $2^{\mathrm{a}}$ ed., Tecnos, Madrid, 2006).

Döhring, Karl, Völkerrecht (2ª ed., C. F. Müller Verlag, Heidelberg, 2004).

Fastenrath, Ulrich, Lücken im Völkerrecht (Duncker \& Humblot, Berlin, 1988).

Goldsmith, Jack L. \& Posner, Eric A., The Limits of International Law (Oxford University Press, Oxford, 2005).

Hegel, Georg Wilhelm Friedrich, Principios de la filosofía del Derecho o Derecho natural y ciencia politica ( $2^{\mathrm{a}}$ ed. Edhasa, Barcelona, 1999).

Hobbes, Thomas, Leviatán o la materia, forma y poder de un estado eclesiástico y civil ( $2^{\mathrm{a}}$ reimp., Alianza Editorial, Madrid, 2011).

Ipsen, Knut, Völkerrecht (C. H. Beck, München, 2004).

Morgenthau, Hans J., Politics among Nations: the Struggle for Power and Peace (7 $7^{\mathrm{a}}$ ed., McGraw-Hill Higher Education, Boston, 2006).

Recasens-Siches, Luis, Tratado general de filosofía del derecho (4⿳亠丷厂 ed., Porrúa, México, 1975).

Seidl-Hohenveldern, Ignaz, Das Recht der Internationalen Organisationen einschließlich der Supranationalen Gemeinschaften ( $7^{\mathrm{a}}$ ed., Carl Heymann Verlag, Köln, Berlin, Bonn, München, 2000).

Tomuschat, Christian \& Thouvenin, Jean-Marc, eds., The Fundamental Rules of the International Legal Order, Jus Cogens and Obligations Erga Omnes (Martinus Nijhoff Publishers, Leiden, Boston, 2006).

Truyol y Serra, Antonio, Historia del derecho internacional público (Editorial Tecnos, Madrid, 1998).

Verdross, Alfred, Universelles Völkerrecht Theorie und Praxis ( $3^{\mathrm{a}}$ ed., Duncker \& Humblot, Berlin, 1984).

Vinogradoff, Paul, Historical Types of International Law, en The Collected Papers of Paul Vinogradoff, with a Memoir by the Right Honorable Herbert Albert Laurens Fisher (Clarendon Press, Oxford, 1923).

Vitzthum, Wolfgang Graf, Völkerrecht (4⿳亠丷厂 ed., De Gruyter Recht, Berlin, 2007).

\section{Colaboración en obras colectivas}

Hillgruber, Christian, Kontinuität und Wandel in der Entwicklung des Völkerrechts, en Recht und Rechtswissenschaft. Signaturen und Herausforderungen zum Jahrtausendbeginn, 117-132 (Peter-Christian Müller-Graff, verlag, Universität Heidelberg, Juristische Fakultät: Recht und Rechtswissenschaft, Heidelberg, 2000).

Kadelbach, Stefan, Jus cogens, obligations Erga Omnes and Other Rules - The 
Identification of Fundamental Norms, en The Fundamental Rules of the International Legal Order, Jus Cogens and Obligations Erga Omnes, 21-40 (Christian Tomuschat \& Jean-Marc Thouvenin, eds., Martinus Nijhoff Publishers, Leiden, Boston, 2006).

Kunig, Philip, Der Rechtsstaat, en Festschrift 50 Jahre Bundesverfassungsgericht, 2 Band: Klärung und Fortbildung des Verfassungsrechts, 421-444 (Peter Badura \& Horst Dreier, hrsg., Mohr Siebeck, Tübingen, 2001).

Tomuschat, Christian, International Law as a Coherent System: Unity or Fragmentation?, en Looking to the Future: Essays on International Law in Honor of W. Michael Reisman, Chapter 18, 323-354 (Mahnoush H. Arsanjani, Jacob Katz Cogan, Robert D. Sloane \& Siegfried Wiessner, eds., Martinus Nijhoff Publishers, Boston, 2011).

\section{Revistas}

Arenal, Celestino del, La teoría de las relaciones internacionales hoy: debates y paradigmas, 22 Revista de Estudios Internacionales de la Universidad de Chile, 86, 153-182 (1989). Disponible en: http://www.revistaei.uchile.cl/index.php/ REI/article/view/15594

Barbé, Esther, El papel del realismo en las relaciones internacionales (La teoría politica internacional de Hans J. Morgenthau), 57 Revista de Estudios Políticos, Nueva Época, 149-176 (1987). Disponible en: http://www.cepc.gob.es/ publicaciones/revistas/revistaselectronicas?IDR=3\&IDN=215\&IDA=16415, https://dialnet.unirioja.es/ejemplar/3269

Bogdandy, Armin von \& Habermas, Jürgen, Diskurstheorie und Völkerrecht: Ein Interview mit Jürgen Habermas, 73 Zeitschrift für ausländisches öffentliches Recht und Völkerrecht, Zä̈RV, 295-303 (2013).

Cremer, Hans-Joachim, Völkerrecht - Alles nur Rhetorik?, 67 Zeitschrift für ausländisches öffentliches Recht und Völkerrecht, ZaöRV, 267-296 (2007). Disponible en: http://www.zaoerv.de/67_2007/67_2007_2_267_296.pdf, http://www.zaoerv. de/67_2007/vol67.cfm

Fassbender, Bardo, The United Nations Charter as Constitution of the International Community, 36 Columbia Journal of Transnational Law, 529-619 (1998). Disponible en: https://www.alexandria.unisg.ch/234620/

Ferrer-Lloret, Jaume, La insoportable levedad del Derecho internacional consuetudinario en la jurisprudencia de la Corte Internacional de Justicia: el caso de las inmunidades jurisdiccionales del Estado, 24 Revista Electrónica de Estudios Internacionales, REEI, Asociación Española de Profesores de Derecho Internacional y Relaciones Internacionales, AEPDIRI, 1-36 (2012). Disponible en: http://www.reei.org/index.php/revista/num24/articulos/insoportable-levedadderecho-internacional-consuetudinario-jurisprudencia-corte-internacionaljusticia-caso-inmunidades-jurisdiccionales-estado

Fischer-Lescano, Andreas, Die Emergenz der Globalverfassung, 63 Zeitschrift für ausländisches öffentliches Recht und Völkerrecht, ZaöRV, 717-760 (2003). Dis- 
ponible en: http://www.zaoerv.de/63_2003/63_2003_3_a_717_760.pdf

Habermas, Jürgen, Die Krise der Europäischen Union im Lichte einer Konstitutionalisierung des Völkerrecht - Ein Essay zur Verfassung Europas, 72 Zeitschrift für ausländisches öffentliches Recht und Völkerrecht, ZaöRV, 1-44, 1 (2012). Disponible en: http://www.zaoerv.de/72_2012/72_2012_1_a_1_44.pdf

Kadelbach, Stefan, Völkerrecht als Verfassungsordnung? Zur Völkerrechtswissenschaft in Deutschland, 67 Zeitschrift für ausländisches öffentliches Recht und Völkerrecht, ZaöRV, 599-621 (2007). Disponible en: http://www.zaoerv. de/67_2007/67_2007_3_a_599_622.pdf

Knauff, Matthias, Konstitutionalisierung im inner - und überstaatlichen RechtKonvergenz oder Divergenz, 68 Zeitschrift für ausländisches öffentliches Recht und Völkerrecht, ZaöRV, 453-490 (2008). Disponible en: http://www.zaoerv. de/68_2008/68_2008_2_a_453_490.pdf

Koh, Harold Hongju, ¿Por qué las naciones obedecen al Derecho Internacional?, 63 Thêmis - Revista de Derecho, 11-50 (2013). Disponible en: http://revistas.pucp. edu.pe/index.php/themis/article/view/8988/9394

Ley, Isabelle, Kant versus Locke: Europarechtlicher und Völkerrechtlicher Konstitutionalismus im Vergleich, 69 Zeitschrift für ausländisches öffentliches Recht und Völkerrecht, ZaöRV, 317-345 (2009). Disponible en: http://www.zaoerv. de/69_2009/69_2009_2_a_317_346.pdf

Mosler, Hermann, Völkerrecht als Rechtsordnung, 36 Zeitschrift für ausländisches öffentliches Recht und Völkerrecht, ZaöRV, 6-49 (1976). Disponible en: http:// www.zaoerv.de/36_1976/36_1976_1_3_a_6_49.pdf

Mouton, Jean-Denis, L'identité constitutionnelle, un concept pertinent au regard du droit international?, 118 Revue générale de droit international public, RGDIP, 3, 501-515 (2014).

Orrego-Vicuña, Francisco, El derecho internacional: entre el cambio y la disolución, 39 Revista de Estudios Internacionales de la Universidad de Chile, 54, 57-66 (2006). Disponible en: http://www.revistaei.uchile.cl/index.php/REI/article/ viewPDFInterstitial/14471/14784

Paulus, Andreas L., Zur Zukunft der Völkerrechtswissenschaft in Deutschland: Zwischen Konstitutionalisierung und Fragmentierung des Völkerrechts, 67 Zeitschrift für ausländisches öffentliches Recht und Völkerrecht, ZaöRV, 695-720 (2007). Disponible en: http://www.zaoerv.de/67_2007/67_2007_3_a_695_720. pdf

Peters, Anne, Die Zukunft der Völkerrechtswissenschaft: Wider den epistemischen Nationalismus, 67 Zeitschrift für ausländisches öffentliches Recht und Völkerrecht, ZaöRV, 721-776 (2007). Disponible en: http://www.zaoerv. de/67_2007/67_2007_3_a_721_776.pdf

Wiegandt, Jan, Internationale Rechtsordnung oder Machtordnung? Eine Anmerkung zum Verhältnis von Macht und Rech im Völkerrecht, 71 Zeitschrift für ausländisches öffentliches Recht und Völkerrecht, ZaöRV,31-76 (2011). Disponible en: http://www.zaoerv.de/71_2011/71_2011_1_a_31_76.pdf 


\section{Tratados internacionales}

Consejo de Europa, Convenio para la Protección de los Derechos Humanos y de las Libertades Fundamentales, Roma, 4 de noviembre de 1950, modificado por los Protocolos 11 y 14, completado por el Protocolo adicional y los Protocolos 4, 6, 7, 12 y 13. Disponible en: http://www.echr.coe.int/Documents/ Convention_SPA.pdf

Organización de Naciones Unidas, ONU, Carta de las Naciones Unidas, San Francisco, 26 de junio de 1945. Disponible en: https://treaties.un.org/Pages/ ViewDetails.aspx?src=TREATY\&mtdsg_no=I-1\&chapter $=1 \&$ clang=_en, http://www.un.org/es/charter-united-nations/

Organización de Naciones Unidas, ONU, Convención de Viena sobre el Derecho de los Tratados, U.N. Doc A/CONF.39/27 (1969), 1155 U.N.T.S. 331, Viena, 23 de mayo de 1969, entrada en vigencia 27 de enero de 1980. Disponible en: http://legal.un.org/diplomaticconferences/lawoftreaties-1969/docs/english/ confdocs/a_conf_39_27.pdf, https://www.oas.org/dil/esp/Convencion_de_ Viena_sobre_derecho_tratados_Colombia.pdf

Organización de Naciones Unidas, ONU, Convención sobre la Eliminación de Todas las Formas de Discriminación contra la Mujer, adoptada y abierta a la firma y ratificación, o adhesión, por la Asamblea General en su resolución 34/180, de 18 de diciembre de 1979. Disponible en: http://www.ohchr.org/SP/ ProfessionalInterest/Pages/CEDAW.aspx

Organización de Naciones Unidas, ONU, Convención sobre los Derechos del Niño, adoptada y abierta a la firma y ratificación por la Asamblea General en su resolución 44/25, Nueva York, 20 de noviembre de 1989. Disponible en: http://www.ohchr.org/SP/ProfessionalInterest/Pages/CRC.aspx

Organización de Naciones Unidas, ONU, Pacto Internacional de Derechos Civiles y Políticos, adoptado y abierto a la firma, ratificación y adhesión por la Asamblea General en su resolución 2200 A (XXI), 16 de diciembre de 1966. Disponible en: http://www.ohchr.org/SP/ProfessionalInterest/Pages/CCPR.aspx

Organización de Naciones Unidas, ONU, Pacto Internacional de Derechos Económicos, Sociales y Culturales, adoptado y abierto a la firma, ratificación y adhesión por la Asamblea General en su resolución 2200 A (XXI), 16 de diciembre de 1966. Disponible en: http://www.ohchr.org/SP/Professional Interest/Pages/CESCR.aspx

Organización de Naciones Unidas, ONU, Protocolo Facultativo de la Convención sobre los Derechos del Niño relativo a la Participación de Niños en los Conflictos Armados, Asamblea General, Resolución A/RES/54/263, 25 de mayo de 2000. Disponible en: http://www.ohchr.org/SP/ProfessionalInterest/ Pages/OPACCRC.aspx

Organización de Naciones Unidas, ONU, Protocolo Facultativo de la Convención sobre los Derechos del Niño relativo a la Venta de Niños, la Prostitución Infantil y la Utilización de Niños en la Pornografía, 25 de mayo de 2000. Disponible en: http://www.unicef.org/spanish/specialsession/documentation/ documents/op_se_sp.pdf 
Organización de Naciones Unidas, ONU, Protocolo Facultativo de la Convención sobre los Derechos del Niño relativo a un Procedimiento de Comunicaciones, Asamblea General, Resolución A/RES/66/138, 19 de diciembre de 2011. Disponible en: https://treaties.un.org/doc/source/signature/2012/a-res-66-138spanish.pdf

\section{Normatividad internacional}

Chile, Constitución, 11 de septiembre de 1980, actualizada por la Ley 20.860, 20 de octubre de 2015. Disponible en: https://www.leychile.cl/ Navegar?idNorma $=242302$

\section{Jurisprudencia internacional}

Corte Internacional de Justicia, CIJ, Reservas a la Convención para la Prevención y la Sanción del Delito de Genocidio, Opinión consultiva de 28 de mayo de 1951. Disponible en: http://www.icj-cij.org/homepage/sp/files/sum_1948-1991. pdf, http://www.dipublico.org/cij/doc/12.pdf

Corte Permanente de Justicia Internacional, CPJI, Sentencia caso Lotus, Asunto del Vapor, Lotus, Francia contra Turquía, Serie A 10, Sentencia de 7 septiembre de 1927. Disponible en: http://www.icj-cij.org/pcij/serie_A/A_10/30_Lotus_Arret.pdf, http://www.icj-cij.org/pcij/serie_other/cpji-pcij.pdf

Direcciones web

http://www.un.org/es/member-states/

https://www.wto.org/english/thewto_e/whatis_e/tif_e/org6_e.htm 